\title{
Introduction: the rule of law in transnational development projects - private actors and public chokeholds
}

\author{
Kinnari Bhatt ${ }^{1}$, Jennifer Lander ${ }^{2}$ and Sanne Taekema ${ }^{3 *}$ \\ ${ }^{1}$ Legal and Compliance (Project Finance, Sustainability), Norinchukin Bank Europe N.V., The Netherlands, ${ }^{2}$ Visiting \\ Research Fellow, School of Law, De Montfort University, Leicester, UK and ${ }^{3}$ Professor of Jurisprudence, Erasmus School of \\ Law, Erasmus University Rotterdam, The Netherlands \\ ${ }^{*}$ Corresponding author. E-mail: taekema@law.eur.nl
}

\begin{abstract}
'large development projects ... raise complex and difficult constitutional questions; specifically, around the capacity of private actors through the contractual, policy and behavioural mechanisms ..., to heavily influence ... democratic governance, law-making and to impact upon the availability, predictability and fairness of basic services in energy, infrastructure and even legal remedy.' (Bhatt, 2020, p. 20)
\end{abstract}

'The way in which investor perceptions about the stability and legitimacy of Mongolia's mining regime have become inculcated within the symbolic and practical dimensions of national governance suggests the triumph of a particular set of normative values associated with "economics imperialism," those which glorify markets and prioritise the reduction of transaction costs... The reductive assessment of Mongolia's legal system in terms of the benefits and stability it offers for foreign investors signifies not only the marketisation of the economy but of the legal system itself.' (Lander, 2020, p. 248)

\section{Introduction}

The impact of the private sector on law and governance has become a major source of interest for legal, political and sociological scholarship in light of its profound implications for states, organisations and individuals (Koskenniemi, 2011; Szablowski, 2007). A welcome new arrival to this wider literature is path-breaking work seeking to examine the intricacies of private law and actors as crucial protagonists in the global political economy and what it means for inequality, vulnerability and power distribution (Pistor, 2020; Linarelli et al., 2018; Cutler, 2018b). Crucially, this body of work reminds us that it is hard to disentangle private actors - and capital - from the state. Locating the agency of private actors is made more difficult in the context of profound levels of legal and economic transnationalism that structure global capital formation, accumulation and distribution. The alignment of transnational legal institutions with private wealth creation has been shown to systemically choke the national demos by sidelining the implementation of citizens' rights and undermining their ability to hold those with power accountable for policies and practices that affect them. What is missing are efforts to identify precisely how private actors produce these outcomes in the real transnational world in which we live. Because the means used are varied, and often combined in non-transparent, arbitrary and intricate ways, it is often hard to see precisely how private actors mobilise legal power, even if we feel the effects. 
Adding to the above trajectory of scholarship, the books by Bhatt and Lander begin to answer this 'how' in the context of transnational development projects (Bhatt, 2020; Lander, 2020). ${ }^{1}$ In so doing, they expose the field of transnational development projects as a living phenomenon that illuminates the machinations of power, capital, bargaining, private laws and bias within the global legal economic architecture. In particular, their work evidences the power of investor preferences to transform the legal relations between the state and private actors, as well as fundamentally re-order legal relations between the state and its citizens. Consequently, the works spark original conversations about the rule of law and the 'constitution-like' legal, political and economic modalities of global capitalism (Schneiderman, 2008, p. 4). Bhatt and Lander highlight the various ways by which private actors (and their lawyers) avail themselves of and use these modalities to cement, prioritise and universalise their legal and regulatory preferences in the context of large-scale extractive and infrastructure development projects, at the expense of public rights and interests. As these monographs show, the categories of international and domestic law - with their respective public and private binaries - cannot be theorised as only existing in undisturbed silos if we are to face the major lacunae that transnational legal orders in the context of development projects create within existing accountability paradigms. This in turns leads us to argue in section 3 for a broadening of the concept of rule of law to enable its use as a critical framework to reveal and assess the arbitrary impacts of transnational exercises of private power on public legal rights and expectations. As the books demonstrate and as highlighted in the next section, the rule-of-law ideal is currently used instrumentally and largely arbitrarily by private actors to further their own proprietary and contractual interests. By highlighting the often exclusionary impacts of this instrumentalised use of the rule of law through the context of the books and the contributions that follow, our aim here is to propose new thinking towards a critical rule-of-law concept that engages with private power relations.

\section{Transnational development projects}

\subsection{Challenging the rule of law}

Today, the rule of law has become one of the most prominent conceptual umbrellas for a range of legal-accountability norms that cover contract enforcement, access to justice, human rights protections, non-discrimination principles and procedural fairness. Its primary purpose is to provide a safeguard against the exercise of arbitrary power by requiring legal foundations for any decision or action by a public authority that impacts the rights and expectations of individuals. The rule of law has consequently been integral to the development of democratic systems of government in national states, and features powerfully within contemporary 'good-governance' promotion in the Global South by development financial institutions (Cutler, 2018b). While the rule of law's conceptual origin and core principle lie in the legal limitation of the exercise of state power in relation to the rights of the individual, ${ }^{2}$ the straightforward application of the concept has been complicated in recent decades with global economic - and legal - integration, where the state is no longer the sole locus of legal power or authority. However, despite this changing global context, the paradigm of the rule of law promoted within mainstream development policy and academic literature continues to reproduce the traditional subject of rule-of-law discourse: the state. Increasingly, the rule of law has become shorthand for stability of contract and the protection of private property rights from the expropriating power of the state in the global political economy, rather than considering the general stability of rights, access to justice and fairness. Drawing on Lander and Bhatt's research, we argue that such a limited focus not only misses the forest for the trees when it comes to transnational development

\footnotetext{
${ }^{1}$ Development projects involving private and public partners are widely deployed in energy and infrastructure settings for instance, to provide renewable energy, oil and gas, natural resources, health, schools, roads, rail and ports.

${ }^{2}$ The rule of law developed as a safeguard for individual life and liberty at a time when monarchs in Europe had extensive arbitrary powers to render lives disposable, as well as being a safeguard for the property rights of the rising merchant class with the rise of modern capitalism.
} 
projects, but actively undermines our collective ability to concretely hold powerful private actors to account for their impact on the legal relations, rights and norms of national publics.

Conscious of the limitations of developing generic frameworks to understand complex and diverse sites of transnational legality, we find within their work some common starting questions and useful categories that can inform further work about the influence of private actors on the rule of law specifically. The books illustrate that, in the context of development projects, pervasive accountability deficits and access-to-justice issues are routinely raised by private actors' use of contracts, ${ }^{3}$ policies ${ }^{4}$ and intermediaries. ${ }^{5}$ Cutting across these categories are private socio-legal cultures of discretionary decision-making that, through their interaction with these three categories, will influence the creation of legal authority and accountability in the context of development projects. In transnational governance processes, all of these categories - contracting, policy formation, intermediaries and discretionary cultures - will overlap and accumulate. Consequently, it can be difficult to pinpoint the locus of power in 'liquid' transnational settings (Krisch, 2017) around legally and economically intensive sites like extractive and infrastructure development projects. Helpfully, however, the interaction between categories and cultural variables produces numerous signals that legal relations have changed and a potential rule-of-law disturbance has arisen. Following Shaffer in his analysis of the impact of transnational legal ordering on the state, we suggest private influence on transnational legal relations can also be evidenced in 'changes in the boundary between the state, the market and other forms of social ordering' (Shaffer, 2014, p. 23). Perhaps not surprisingly, new 'boundary signals' are deeply related with the role of private expertise in new associational patterns in governance (Shaffer, 2014). These themes will be discussed in the following section in relation to the authors' books.

\subsection{Rule of law reset towards private actors and interests: contributions from the books}

Lander's study provides new theoretical insight and in-depth empirical analysis about the toxic relationship between transnational legality, state change and the globalisation of markets. With specific reference to Mongolia's recent transformation as a mineral-exporting country, she traces the way in which distinctive transnational legal processes have re-ordered and reframed the governance of Mongolia's mining sector towards the protection and promotion of private foreign capital investment, at the expense of national developmental and democratic priorities. At the heart of these processes of transnational legal ordering are investment contracts that effectively bind state parties into a transnational legal regime of investment protection and promotion that exists and is enforced beyond the national state. At the same time, the national state itself is transformed by its new intimacy with global capital, which extends beyond the site of extraction itself to order relations between the central government, subnational administrations and civil society in a way that aligns with the priority of the private sector in securing 'stable' conditions for investment and business.

\footnotetext{
${ }^{3}$ With a distinct counterparty or counterparties (state, financial institutions, individuals or both) with the terms of that legal association reinforced through an express choice of law and enforcement mechanism (court or arbitral, or both).

${ }^{4}$ These differ from contracts as they do not involve bilateral and legally enforceable obligations. Typically, they are the outcome of negotiations between a group of commercial or industry participants (and, in some cases, affected parties) with a view to filling a legal or regulatory gap through self-regulating actions in relation to a specific issue. Application of policies is done on a soft voluntary basis with limited ability for affected communities to hold private entities to account for noncompliance with those policies. In some cases, such as for environmental and social safeguarding standards, that policy will then be legally formalised within a contract between commercial parties that is governed by an express choice of law and enforcement regime.

${ }^{5}$ For instance, when private actors pay environmental and social experts to provide advisory reports that drive corporate decision-making on local issues such as resettlement, housing or public health, engage private law firms to draft and negotiate contracts, and use project grievance mechanisms to dispense mediation and accountability to third parties. Examples include the Equator Principles Finance Institutions and Dutch Banking Sector Association on environmental and social safeguarding standards, the Independent Accountability Mechanisms Network dispensing grievance redress and accountability in the financial sector and the Loan Market Association, Independent Swaps and Derivatives Association providing standardised documentation and credit-rating agencies such as Moody's providing investment grading.
} 
Notably, for Lander, extractive development is not the rollback, outsourcing or hollowing-out of the state, but its total expansion and transformation through the private market and its pathologies. In this sense, legal and regulatory reforms and national decision-making become dedicated to securing foreign direct investment in extractive development projects by developing a comprehensive legal and political bulwark against any public 'threats'. This complete transformation in public governance reorientates national law to prioritise and preserve investor confidence instead of the confidence of the national demos, which become a new type of 'outsider' that is increasingly locked out of legal influence by a passive state and the watertight web of project-specific investment protections secured through contracts and investment treaties. This gives extractive development sites - and the economic strategy as a whole - a constitutional quality in which redistributions of power and resources occur outside of democratic scrutiny and within tightly secured private and bureaucratic legal structures and relations that are infused with the regulatory preferences of investors.

Bhatt's study extends a broad socio-legal-economic analysis of the phenomenon of development projects. She navigates the private and public 'hyper plurality of norms' and the power and practices at play within these projects as they interface with the implementation and recognition of indigenous peoples' rights to land to create a unique global jurisprudence of indigenous rights for development projects. Foregrounding the use of 'extra-legal' contracts such as debt instruments, construction contracts, guarantees, concessions and power purchase agreements (and specific clauses within these contracts) that are entered into between the project company and its investors, Bhatt shows how contracts consolidate power and patronage with investors, providing helpful signals for understanding how private actors provoke rule-of-law disturbances.

Illustrated through technical detail and case-studies in Mongolia, Panama and Uganda, amongst others, these contracts create multiple entry points through which the land rights of indigenous peoples are routinely sidelined. Intertwined with contracting, Bhatt shows how financial investors and companies work in a 'club' to require the use of standardised debt and security documentation coded and negotiated within expensive legal offices. Weaving into those contracts are the environmental and social safeguarding policies of international financial institutions, which are then operationalised within the contracts at specific times that are often too late to have rights-compliant impacts for communities. Throughout the long project life-cycle, the company will deploy intermediaries: law firms and environmental and social experts to provide reports that will ultimately support the implementation of contracts and policies.

Pervading these projects are different kinds of behaviour based in the culture and social context of doing business with private actors. Socio-legal scholarship has already identified some of them. These include an emphasis on mathematisation and quantification through the deployment of indicators (Perry-Kessaris, 2011), a tick-box approach to social impacts as part of a wider 'loan-approvals culture' (Sarfaty, 2012) within international financial institutions that disincentivises engagement with social policies that can slow down project approval and financial completion, and an 'audit culture' (Shore and Wright, 2015) that sees consultants, ombudsmen and mediators applying soft standards and gapfilling policies in private economic and social governance roles. Drawing on these insights, both authors further highlight how bargaining and patronage take shape in development-project contexts.

For Bhatt, this takes shape early on in project design, through a wider and highly technical 'contracts culture' that is negotiated within law firms and further embedded within multiple legal and socio-legal practices that translate investor preferences. These include contractual provisions that permit investors to deploy market-standardised documentation that prioritises investor social safeguarding policies over local laws and international legal standards. This documentation permits the waiver of contractual clauses that operationalise social safeguarding standards at crucial moments for rights implementation. Investors (supported by hired intermediaries) are then able to label communities as 'vulnerable' instead of 'indigenous'. To this, she observes a wider culture of negotiation, discretion, algorithmic modelling, language choice and a culture of poor timing within project design. Bhatt illustrates how these cultures compound to make purposeful free, prior and informed-consent rights and processes illusory for indigenous communities in practice (Bhatt, 2020, chapters 4, 5). 
For Lander, private patronage is entrenched through multiple transnational legal measures inculcated within the domestic legal and policy sphere that actively undermine domestic sources of resistance and incentivise political elites to participate in new multi-stakeholder fora. These fora are introduced through corporate initiatives or through the more concerted 'good-governance' reform efforts of international financial institutions. The broad-based domestication of transnational legal measures through legislation and policy-making is an important counterpart to the investment contracts and project finance agreements that structure specific projects. Their effect can be seen through the way in which investors and international financial institutions have sought to heavily influence modes of negotiation both with public authorities on issues of mining and investment policy, as well as with local communities with regard to project-specific economic or socio-environmental impacts. Notably, these modes of conflict resolution and dispute settlement veil power dynamics and inequalities between the parties, and diffuse conflicts away from national public debate towards parcelised 'alternative stakeholder-based forums which are issue-, identity- and interest-based' (Lander, 2020, p. 218). The national and subnational promulgation of these modalities of conflict 'resolution' and consensus-building profoundly shapes the possibility of challenging the terms of an extractive development project as a whole.

Highly apparent from these books is that the private sector's use of contracts, policies and intermediaries is not the fragmented extra-legal process that international lawyers perceive them to be, but is a carefully harmonised, impregnable legal contractual network that interacts with and constricts constitutional guarantees, legislative provisions and public policies at the national level. As Bhatt illustrates, formal legal frameworks for instance on indigenous peoples' land rights have not been able to cope with private contracts on debt for instance that are backed by the threat of legal enforcement through express English or New York law governing law clauses. Where recourse to foreign courts is not available for instance in host-state agreements, these contracts are, through negotiation, infused with clauses that will limit or reduce the application of local law. ${ }^{6}$ The state will accept these concessions in order to attract foreign investment. Consequently, investors will be able to elect court or arbitral enforcement mechanisms, with the latter being favoured for their flexibility, confidentiality and ability for the arbitrators to consider the project and its legal documentation as whole. The cumulative impact of these overlapping contracts, policies, intermediaries and socio-legal cultures is to form an assemblage of almost algorithmically engineered ring-fenced development-project legal structures. These structures are ordered and negotiated far upstream in project design, entrench a generalised quality for protecting investor confidence over all other values and, in so doing, displace local realities.

Beyond the extractive project itself, the international protections available to private actors to protect investments also construct a powerful legal discourse about their victim status in relation to 'rule-of-law breaches' by national states in the context of investor-state disputes. Lander argues that investor perceptions of state behaviour have huge sway over the perceptions of international intermediaries, such as credit-ratings agencies and financial media outlets, which construct discursive frames of 'innocent investors' and 'pariah states', as demonstrated in the case of Mongolia. Alongside the bulwark of transnational legality that protects investor rights, this normative discourse exerts significant pressure on national states to adopt policies and investment-protection legislation, as well as provide further concessions, where reputation protection is critical to sustain foreign capital flows.

Both books highlight the futility of the conceptualisation of law into neat public and private, state and non-state categories when it comes to dealing with issues of inequality, distribution and exclusion in today's pluralised legal and social settings. They also highlight the challenge of conceptualising the role of the state in this transnational plural legal context. This is because the characteristic of the state in this context is simultaneously one of passivity (towards non-economic values) and expansiveness (towards pro-market values). Led by the private logic of enterprise, the state redistributes core democratic principles of consent, co-operation and participation away from local actors towards international 'experts', private technical specialists and their contractual toolkit that is capable of supposedly 'neutral'

${ }^{6}$ Bhatt (2020, p. 47) shows how these clauses work. 
and efficient decision-making. In this sense, the books contribute to a wider conversation in transnational legal theory that shows how traditional state-based systems of law no longer enjoy a monopoly on the creation of legal authority, relations and the enforcement of those associations.

The books operationalise a methodological approach to transnational law, drawing on the work of scholars who theorise transnational legality as a cross-border ordering process rather than referring to a new 'sphere' or 'scale' of law. For example, the books draw on work by Shaffer and Zumbansen, who show how both public and private 'actors, norms and processes' shape 'border-crossing regulatory regimes' (Zumbansen, 2012, p. 312) with 'legal norms that apply across borders to parties in more than one jurisdiction' (Shaffer, 2014, p. 6). Notably, these conceptions of legal transnationalisation are not limited to traditional international law, but also capture 'the interaction of publicly and privately made law' (Zumbansen, 2013, p. 29). Halliday and Shaffer's extensive work on transnational legal ordering is useful to conceptualise how networks of public and private actors involved in lawmaking exert extraordinary influence to order legal relations across borders (Shaffer, 2014; 2016; Halliday and Shaffer, 2015). As Lander notes, 'the emphasis on ordering focuses energy on tracing legal normative diffusion through stages of "construction, flow and settlement" rather than primarily seeking to establish a new category or scale of law' (Lander, 2020, p. 6, emphasis in original, citing Shaffer, 2016, p. 237).

Drawing on Cutler, we argue that the transnational cannot really be seen as a separate legal sphere, but should rather be regarded as a space in which various forms of law and regulation - public, private, hard, soft, national, international - interact (Cutler, 2018a, p. 67). This conception is useful for distinguishing Bhatt and Lander's contextual analysis of transnational development projects from other contributions that focus on 'global law' as a distinct legal sphere (Cassese, 2015) or soft-law business and human rights 'due-diligence' approaches that are developed almost exclusively through an international human rights framework that continues to centre the state as the key legal actor.

To conclude this section, the transnationally induced rule-of-law reset analysed in these books exposes a unique coercive quality around development projects, which undermines rule-of-law principles such as fairness, rights realisation and access to justice. Despite constitutional and international guarantees to the contrary, public access to and participation in critical decision-making about the governance of development projects is actively redistributed towards international financial institutions and private investors. In this context, the books demonstrate how transnational law allocates domestic political, economic and legal resources in the context of development projects. In their different yet complementary ways, these books show how private legal norms have cemented themselves into local socio-legal environments to influence identity, community and citizenship status, participation, access to remedy and even allocation of resources on an intergenerational level.

\section{Rethinking the rule of law in a transnational legal context}

Through the analysis of transnational development projects, a different image of the rule of law appears. In this setting, the rule-of-law concept is appealed to in a specific way that narrows it down to the protection of the interests and expectations of powerful, for-profit private actors. However, the books clearly indicate the need to criticise this use - a criticism that can potentially generate a broader and richer conceptualisation of the rule of law. The main point of such a reconceptualisation is to bring the activities of powerful private actors within the scope of the rule of law and criticise their actions on the basis of rule-of-law standards.

A useful starting point for broadening the rule-of-law concept beyond the state is the idea of arbitrary power. As Selznick and Krygier have argued in their socio-legal work, the core purpose of the rule of law is to curb the arbitrary exercise of power (Selznick, 1961; 1969; Krygier, 2016). The various

\footnotetext{
${ }^{7}$ Even though some soft law has hardened into binding law, e.g. recent laws requiring companies to report on modern slavery practices within their supply chains, the soft due-diligence approach would not consider the potential of contracts to sideline human rights in transnational business contexts, as Bhatt (2020) notes at p. 77.
} 
principles associated with the rule of law, such as generality of norms, protection of rights or access to justice, can all be interpreted as contributing to this rule-of-law 'telos' (Krygier, 2009; 2011). While, traditionally, it is the state that was seen as the main source of arbitrariness, it is clear from the prevenient discussion that the state no longer has a monopoly on it. A recurring theme when it comes to development projects and investment particularly is that the public actors involved do not usually have the upper hand and the arbitrariness is more apparent in the conduct of the private actors, as Lander and Bhatt's work demonstrates. Such observations question the automatic identification of the state as the actor that should be held to rule-of-law standards and invite consideration of the way in which law can provide means to reign in private arbitrary power as well. Consequently, if we focus on the type of action (arbitrariness) rather than the type of actor, it is possible to see how a rule-of-law concept could be developed that more comprehensively addresses multiple sources of arbitrariness and unaccountability in legal relations.

This approach to the rule of law has greater carrying capacity for application in the transnational economic and legal world in which we live. Addressing sources of arbitrary power impacting legal relations calls for a contextual assessment of the problems in a particular area (cf. Selznick, 2003), of the constellation of actors involved and the power dynamics among them, of which the two books provide numerous examples. Private actors' invocation of a narrow rule-of-law framework - only focused on the state - in order to exclusively protect their property rights and profitability can be exposed as potentially contributing to other rule-of-law problems such as the limitation of constitutional rights through the contracts, policies, intermediaries and organisational cultures discussed within these books. That traditional rule-of-law approaches do not consider the impacts of power within these pluralised transnational contexts is problematic for understanding the many ways in which private actors instrumentalise legal power and alter legal relations and accountability paradigms in today's global political economy. The following commentators will discuss how they understand our central enquiry about the arbitrary exercise of power by private actors within the context of the books and their own transnational research reflections.

\section{Introducing the contributions to this symposium}

This book symposium has its roots in a webinar hosted by the INFAR project in the spring of $2020 .{ }^{8}$ It replaced a broader plan for a transnational rule-of-law conference that was cancelled due to the Covid-19 crisis. As this introduction has outlined, the symposium is a conversation about two books by Kinnari Bhatt and Jennifer Lander through a rule-of-law lens. Bhatt and Lander's books question the unaccountable exercise of private power in the social context of development projects, which are concentrated sites of transnational legal and economic activity. The contributors to the symposium were asked to link the books to the themes that concern them in their own work and to consider aspects of transnational law and rule of law.

In response to the provocation of the books, the eight interventions in this symposium ask how the empirical reality of private actors' power to arbitrarily disrupt public rules, rights and realities could stimulate new thinking about the rule of law as a concept. The symposium captures a range of new theoretical perspectives, empirical contexts, further applications to other development projects as well as lively critique about the idea that private actors should be held accountable to rule-of-law norms.

The first two contributions, by Ilias Bantekas and Chantal Mak, reflect on the ideas and empirical analysis developed in the books about transnational law. Where Bhatt and Lander tend to focus on transnational law as a process that shapes economic and social relations in the context of development projects, Bantekas and Mak both approach transnational law as a separate sphere. Bantekas argues that the books' case-studies illustrate what he argues is a larger ongoing process of contractualising international law. This process may be fruitfully framed by a theory of transnational law as a sphere

\footnotetext{
${ }^{8}$ INFAR refers to a research project funded by Erasmus University investigating the integration of normative and functional approaches to the rule of law and human rights (2015-2020), led by Sanne Taekema and in which Kinnari Bhatt was a co-ordinating postdoctoral researcher.
} 
of contracts in which states and private actors meet to avoid the constraints of public law. He compares Bhatt's case-study of indigenous land rights to state finance to show how mechanisms of contractualisation undermine the bargaining power of states and indigenous peoples alike. Mak discusses the books as a starting point for a transnational rule-of-law theory that draws on the justice-based globalgovernance concept of Nancy Fraser. Noting the clear dangers for entrenching capitalist premises by including the 'wild zones' in which companies conduct their business as part of transnational legal regulation, Mak argues that the inclusion of these zones and a focus on the actors and affected communities within them would hold promise for better locating and localising rule-of-law problems in situ.

Where Mak calls for participation of people affected by transnational governance, Gamze Erdem Türkelli critiques the role of financiers in brokering public-private relationships in development projects from a human rights perspective. She criticises the selective use of human rights by financiers and argues for the institutional empowerment of disadvantaged groups as a form of resistance to the dominance of financial actors. In his contribution, John Harrington extends Lander's framework on the relationship between transnational law and material constitutional change to a new context: global health projects in Kenya. Harrington shows how transnational law infuses global health projects, notably through contractual relations, to shape constitutional outcomes. In this way, he demonstrates how transnational legality acts as a process through the national sphere to put 'cross-border [health] research collaboration beyond the reach of domestic law', in a similar way as commercial contracts serve to insulate development projects from public legal influence.

From the critical appraisal of rule-of-law aspects of development projects, a particular issue that arises is the extent to which the private-law mechanisms - particularly the use of contract and property rights - can be improved. Johanna Cortés-Nieto and Giedre Jokubauskaite take a sceptical view and argue that the rule-of-law paradigm cannot be disentangled from its historical origin in liberal modern worldviews and capitalist rationality, drawing on insights from a case-study in Colombia. Consequently, whilst a critical rule-of-law perspective does raise important issues, they argue that it ultimately entrenches existing privileges and perpetuates inequalities because the ideal of the rule of law cannot be separated from its connection with specific institutions and values. Martijn Scheltema, on the other hand, takes a more optimistic view of working with the private-law instruments that have been developed to provide remedies. In his paper, he sketches how accountability to affected peoples could be organised in a way that aligns the interests of private actors and public governance. Federica Violi addresses the question of how property and contract operate in the investment context, bringing the focus to investor-state relationships and the consequences for land rights. Building on the work by Bhatt and Lander, she argues for a reconceptualisation of these relationships as triangular, including affected populations and their rights to land and resources. Finally, Paul Burgess critically evaluates the central underlying claim of this whole issue: that a rule-of-law framework can be used to understand and assess the role of private actors in development. He argues that the rule of law is conceptually tied to state power and cannot be applied to private actors, even when like Google - they may be as powerful as states in practice.

All of these contributions offer vital interlocutions on the urgent question of how private power is conceptualised and practised in an increasingly complex world of transnational legal relations and economic transactions. The range of debates and applications engaged in these pieces is testament to the pertinence of the socio-legal work undertaken within the books and the need to address major, systemic gaps within existing frameworks of accountability such as the rule of law.

Conflicts of Interest. None

Acknowledgements. The authors would like to thank the participants in the webinar on Private Actors and the Rule of Law on 12 June 2020 for their ideas and comments.

\section{References}

Bhatt K (2020) Concessionaires, Financiers and Communities: Implementing Indigenous Peoples' Rights to Land in Transnational Development Projects. Cambridge: Cambridge University Press. 
Cassese S (2015) Research Handbook on Global Administrative Law. Cheltenham: Edward Elgar.

Cutler AC (2018a) The judicialization of private transnational power and authority. Indiana Journal of Global Legal Studies 25, 61-95.

Cutler AC (2018b) The rule of law, new constitutionalism, and transnational legality. In May C and Winchester A (eds), Handbook on the Rule of Law. Cheltenham: Edward Elgar, 307-320.

Halliday TC and Shaffer G (2015) Transnational Legal Orders. New York: Cambridge University Press.

Koskenniemi M (2011) Empire and international law: the real Spanish contribution. University of Toronto Law Journal 61, $1-36$.

Krisch N (2017) Liquid authority in global governance. International Theory 9, 237-260.

Krygier M (2009) The rule of law: legality, teleology, sociology. In Palombella G and Walker N (eds), Re-locating the Rule of Law. Oxford: Hart, pp. 45-70.

Krygier M (2011) Four puzzles about the rule of law: why, what, where? And who cares? In Fleming J (ed.), Getting to the Rule of Law. New York: New York University Press, pp. 64-104.

Krygier M (2016) The rule of law: pasts, presents and two possible futures. Annual Review of Law and the Social Sciences $\mathbf{1 2}$, 199-229.

Lander J (2020) Transnational Law and State Transformation: The Case of Extractive Development in Mongolia. London: Routledge.

Linarelli J, Salomon ME and Sornarajah M (2018) The Misery of International Law: Confrontations with Injustice in the Global Economy. Oxford: Oxford University Press.

Perry-Kessaris A (2011) Prepare your indicators: economics imperialism on the shores of law and development. International Journal of Law in Context 7, 401-421.

Pistor K (2020) The value of law. Theory and Critique 49, 165-186.

Sarfaty G (2012) Values in Translation: Human Rights and the Culture of the World Bank. Stanford: Stanford University Press.

Schneiderman D (2008) Constitutionalizing Economic Globalization: Investment Rules and Democracy's Promise. Cambridge: Cambridge University Press.

Selznick P (1961) Sociology and natural law. Natural Law Forum 6, 84-108.

Selznick P (with Nonet P and Vollmer H) (1969) Law, Society and Industrial Justice. New York: Russell Sage Foundation.

Selznick P (2003) 'Law in context' revisited. Journal of Law and Society 30, 177-186.

Shaffer G (2014) Transnational Legal Ordering and State Change. Cambridge: Cambridge University Press.

Shaffer G (2016) Theorizing transnational legal ordering. Annual Review of Law and the Social Sciences 12, $231-253$.

Shore C and Wright S (2015) Governing by numbers: audit culture, rankings and the new world order. Social Anthropology 23, 22-28.

Szablowski D (2007) Transnational Law and Local Struggles: Mining, Communities and the World Bank. Oxford: Hart.

Zumbansen P (2012) Defining the space of transnational law: legal theory, global governance, and legal pluralism. Transnational Law and Contemporary Problems 21, 305-336.

Zumbansen P (2013) Lochner disembedded: the anxieties of law in a global context. Indiana Journal of Global Legal Studies 20, 29-69.

Cite this article: Bhatt K, Lander J, Taekema S (2021). Introduction: the rule of law in transnational development projects private actors and public chokeholds. International Journal of Law in Context 17, 91-99. https://doi.org/10.1017/ S1744552321000021 